\title{
Reasons for current pregnancy amongst grand multiparous Gambian women - a cross sectional survey
}

\author{
Patrick Idoko ${ }^{1,2^{*}}$, Glenda Nkeng ${ }^{2}$ and Matthew Anyawu ${ }^{1,2}$
}

\begin{abstract}
Background: While grand multiparity is now relatively rare in the developed world it is still common in Sub Saharan Africa. Although significant resources have been committed to providing modern contraceptive methods in the Gambia, the total fertility rate is still high at 5.6. Determining the reasons grand multiparous women proffer for the current pregnancy may help in understanding this trend and tailoring appropriate messages to address any specific concerns.
\end{abstract}

Method: A cross sectional survey of grand multiparous women was carried out at the Royal Victoria Teaching Hospital (now Edward Francis Small Teaching Hospital) to determine the reasons for the current pregnancy.

Results: The prevalence of grand multiparity was $26.5 \%$ while the average parity among the study population was 7.2 (sd 1.8). The most common reasons given for the current pregnancy were: the desire for another child (22.8 \%), the pregnancy was unplanned - a "mistake" (18.4\%) and the need to replace a dead child (15.4\%).

Conclusion: Grand multiparity is still very common in The Gambia. Additional efforts are required to target those with unplanned pregnancies. Improving child survival may also decrease the prevalence of grand multiparity.

Keywords: Grand multiparity, Reasons, Gambia, Contraception

\section{Background}

A grand multiparous woman is one who has carried five or more pregnancies to the age of viability [1]. Although grand multiparity does not necessarily end in adverse pregnancy outcomes, studies in Sub-Saharan Africa show that it remains a significant contributor to maternal and perinatal morbidity and mortality [2-4]. It is associated with maternal anaemia in pregnancy, antepartum haemorrhage, abnormal foetal presentation, postpartum haemorrhage as well as medical conditions such as hypertension in pregnancy [2-4]. The grand multiparous woman is also more likely to require a surgical obstetric intervention with its attendant risks [5]. In addition, there are associated perinatal problems including low birth weight, preterm birth and congenital malformations [7].

\footnotetext{
* Correspondence: patidoko@gmail.com

${ }^{1}$ Edward Francis Small Teaching Hospital, Independence Drive, Banjul, The Gambia

${ }^{2}$ School of Medical and Allied Health Sciences, University of The Gambia, Independence Drive, Banjul, The Gambia
}

The risks associated with grand multiparity have been significantly reduced in developed countries since Bethel Solomons first described the phenomenon as the "dangerous multipara" in 1934 [1, 6]. Current incidence in these settings now ranges from 3 to $4 \%$ [8]. This is due to the high literacy level, availability of modern contraceptive methods, liberal abortion laws and the improved health care services which ensure the survival of almost all children $[9,10]$. High parity is however still a common problem in obstetric practice in many developing countries with incidence ranging from 17 to $33 \%$ in Sub-Saharan African countries [5, 11, 12]. Thus, grand multiparity could be seen as an indicator of low literacy, poverty and other forms of injustice and inequity faced by women in the developing world. Programs aimed at empowering women such as girl child education take a while to drastically create a significant dent in the grim maternal mortality statistics from Africa. Thus, improving access to effective family planning methods remains one 
Table 1 Demographic characteristics of study participants

\begin{tabular}{|c|c|c|}
\hline Age group & Frequency & Percent \\
\hline$>20-25$ & 3 & $2.2 \%$ \\
\hline$>25-30$ & 14 & $10.4 \%$ \\
\hline$>30-35$ & 55 & $40.4 \%$ \\
\hline$>35-40$ & 48 & $35.3 \%$ \\
\hline$>40-45$ & 15 & $11.0 \%$ \\
\hline$>45$ & 1 & $0.7 \%$ \\
\hline Total & 136 & $100.0 \%$ \\
\hline Mean Parity & $7.2(\mathrm{sd} 1.8)$ & \\
\hline Average number of children alive & $5(\mathrm{sd} 2.1)$ & \\
\hline Education & Frequency & Percent \\
\hline None & 42 & 30.9 \\
\hline Arabic School only & 34 & 25.0 \\
\hline Primary School & 27 & 19.9 \\
\hline Middle School & 26 & 19.1 \\
\hline High School & 7 & 5.1 \\
\hline Total & 136 & 100.0 \\
\hline Occupation & Frequency & Percent \\
\hline Petty trader & 56 & 41.2 \\
\hline Cashier & 2 & 1.5 \\
\hline Civil Servant & 1 & 0.7 \\
\hline Farmer & 17 & 12.5 \\
\hline Housewife & 46 & 33.8 \\
\hline Manual Worker & 7 & 5.2 \\
\hline None & 1 & 0.7 \\
\hline Nurse & 2 & 1.5 \\
\hline Teacher & 4 & 2.9 \\
\hline Total & 136 & 100.0 \\
\hline Residence & Frequency & Percent \\
\hline Rural & 40 & 29.4 \\
\hline Urban & 96 & 70.6 \\
\hline Total & 136 & 100.0 \\
\hline Place of delivery in last pregnancy & Frequency & Percent \\
\hline Home & 9 & 6.6 \\
\hline Hospital & 127 & 93.4 \\
\hline Total & 136 & 100.0 \\
\hline \multicolumn{3}{|l|}{ Antenatal clinic attendance in last pregnancy } \\
\hline Yes & 135 & 99.3 \\
\hline No & 1 & .7 \\
\hline Total & 136 & 100.0 \\
\hline Contraceptive counseling in last pregnancy & Frequency & Percent \\
\hline No & 59 & 43.4 \\
\hline Yes & 77 & 56.6 \\
\hline Total & 136 & 100.0 \\
\hline
\end{tabular}

of the cardinal "quick fix" strategies available in the fight to reduce maternal mortality.

The Gambian National Reproductive Health Policy provides for the provision of free family planning services in all the health centres in the country. Despite this huge investment in family planning by the government and international donors, grand multiparity remains a common feature of obstetric practice in The Gambia. The crude birth rate is $27 / 1000$ population while the total fertility rate is 5.6 births per woman [13]. According to WHO estimates, the maternal mortality rate in The Gambia is 430/100,000 live births [14]. The commonest causes of these maternal deaths in the hospital are obstetric haemorrhage, hypertensive diseases in pregnancy and sepsis $[15,16]$.

Studies from other parts of Sub-Saharan Africa have alluded to various reasons for the current pregnancy amongst grand multiparous women. Prominent amongst these are: the desire for large family size, the desire to have a child for a new husband, gender preferences, loss of a child and failed contraception [17, 18]. This study aimed to describe the reasons for the current pregnancy amongst grandmultiparous women at the antenatal clinic of the Royal Victoria Teaching Hospital (RVTH). The study also assessed the contraceptive knowledge and beliefs about contraception of grand multiparous women.

\section{Method}

The study was conducted at the RVTH (now Edward Francis Small Teaching Hospital), Banjul, The Gambia. RVTH is the only tertiary health facility in The Gambia serving its 1.7 million population. The country is a narrow strip of land bordered on three sides by Senegal with a strip of coastline bordering the Atlantic Ocean. RVTH offers primary health care services to women in the greater Banjul area and also serves as the main referral centre for specialized tertiary maternity and reproductive health services.

A structured, pre-tested interviewer administered questionnaire was used (see Additional file 1: Questionnaire: reasons for current pregnancy amongst grand multiparous Gambian women). The questionnaire was verbally translated into the local languages for those illiterate in English. Ethical approval for the study was obtained from the Royal Victoria Teaching Hospital Ethics Committee before commencement of the study. Written, signed informed consent was obtained from each participant prior to the first study procedure. Information was read to the non-literate and translated verbally into their local language of choice. These individuals were then required to thumb print the consent form. 


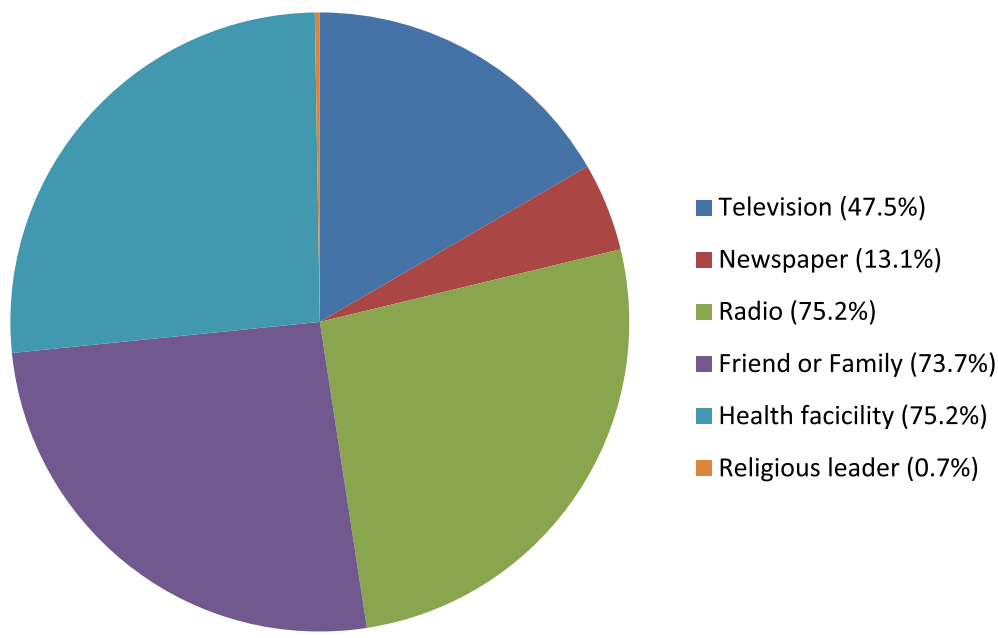

Fig. 1 Source of contraceptive knowledge amongst study participants

\section{Results}

A total of 136 grand multiparous women were seen during the study period from a total of 514 antenatal bookings (prevalence of grand multiparity $-26.5 \%$ ). The mean age of the study population was 35.5 years (sd 4.3). Table 1 details the demographic characteristics of the study population.

One hundred and thirty two $(97.1 \%)$ reported having previously heard of family planning. Common sources of knowledge of family planning were the health facility and radio (Fig. 1).

Common stories related to contraception that these women had encountered are presented in Table 2, while Table 3 shows the beliefs of participants regarding contraception.

Less than half (44.9\%) of the study participants had used a modern method of family planning in the past (Table 4). The main reasons given for not using contraception were fear of side effects $(33.3 \%)$, refusal of partner $(17.3 \%)$ and religious beliefs (16.0\%) (Table 5). Common reasons given for the current pregnancy were a desire for more children, death of another child and "mistake" (Table 6).

While 95 (69.9\%) of the participants were willing to use a contraceptive method at the end of the current pregnancy, $40(29.4 \%)$ were not willing to use any method and one person $(0.7 \%)$ was undecided.

Seventy-five $(55.1 \%)$ said their partner would support their decision regarding family planning while 51 (37.5\%) said partner would not support their decision and $10(7.4 \%)$ were unsure.

\section{Discussion}

The prevalence of grandmultiparity in our study was $26.5 \%$. This is similar to other studies conducted in the sub-region with prevalence ranging from 17 to $33 \%[5,11,12]$. However, in developed countries, grand multiparity is comparatively lower ranging from 3 to $4 \%$ [8]. This difference has been attributed to disparity in literacy level, health care services, availability, accessibility of modern contraceptive methods and differing abortion laws [9, 10].

Evidence of adverse pregnancy outcome in high parity is overwhelming and the risk is higher for great grand multiparous women with over ten children compared to grand multiparous women [4, 19-22]. These obstetric complications include hypertension, gestational diabetes, abruptio placenta, placenta praevia, foetal macrosomia,

Table $\mathbf{2}$ Common stories about contraception that the participants have heard

\begin{tabular}{ll}
\hline & Prequency \\
\hline It causes menstrual abnormalities & 15 \\
It causes severe diseases including cancer & 33 \\
It is effective in child spacing & 49 \\
It decreases the potential for subsequent fertility & 20 \\
It is unreliable (fails easily) & 8.3 \\
It is forbidden on religious grounds & 36.0 \\
It generally improves health & 6.9 \\
\hline
\end{tabular}


Table 3 Beliefs about contraception by participants

\begin{tabular}{llllll}
\hline & Strongly agree & Agree & undecided & Disagree & Strongly disagree \\
\hline Contraception is against my religious belief & $26(19.1 \%)$ & $36(26.5 \%)$ & $36(26.5 \%)$ & $18(13.2 \%)$ & $20(14.7 \%)$ \\
Contraceptives can prevent subsequent pregnancy & $15(11.0 \%)$ & $28(20.6 \%)$ & $28(20.6 \%)$ & $22(16.2 \%)$ & $43(31.6 \%)$ \\
Contraception causes serious illness & $21(15.6 \%)$ & $30(22.2 \%)$ & $38(28.2 \%)$ & $24(17.8 \%)$ & $22(16.3 \%)$ \\
\hline
\end{tabular}

multiple pregnancy, labour dystocia, uterine rupture and perinatal death [4, 19-21]. Grand multiparity and great grand multiparity are independent risk factors for labour dystocia and perinatal mortality [19].

In our study, the majority $(55.9 \%)$ had no formal education and only $6.6 \%$ had a civil job. The majority were housewives $(33.8 \%)$ and petty traders (41.2\%). These findings correlate with previous studies that had implicated poverty; poor education and ignorance as the driving force for low uptake of contraceptives and "mistake" as a reason for index pregnancy as seen in this study [17].

The most common reasons given for the current pregnancy were a desire for more children, death of another child or a "mistake" (Table 6). This finding is similar to a Nigerian study that found that women were willing to get pregnant again if their child died or to have a large family [17]. Traditionally, The Gambia is largely an agrarian society that practices subsistence farming. Therefore, a high premium is placed on having a large family size to help with the farm work. Women who said the current pregnancy was a "mistake" are likely implying that they were not ready to get pregnant at the time they got pregnant. This might be highlighting an unmet need for contraception. Knowledge of contraceptive methods (Fig. 2) was however quite high (80\% were aware of pills) but more than $30 \%$ were worried about the side effects, which prevented them from using contraceptives. It is also pertinent to note that more than $45 \%$ believed that contraceptive use was against their religious dogma and $37 \%$ thought that the use of contraceptives would lead to serious illness. The Gambia is predominantly a religious country and religious leaders are as a result very important opinion leaders. Effective communication and advocacy is necessary to get women to practice contraception. Involving

Table 4 Methods of contraceptives used in the past by study participants

\begin{tabular}{llc}
\hline & Frequency & Percentage (\%) \\
\hline Injectable & 27 & 44.3 \\
Pills & 27 & 44.3 \\
IUD & 7 & 11.4 \\
\hline
\end{tabular}

religious leaders in this process will likely be key in ensuring uptake, as has been the case for other interventions such as uptake of oral polio vaccine [23]. Given the patriarchal nature of Gambian society, men will also need to be targeted in effective family planning sensitization campaigns as almost $20 \%$ of women were not using contraceptives because their partners did not give them permission.

Our data suggests little awareness of male and female sterilization in study participants. As over $90 \%$ of the participants had their last delivery at a health facility, a case could be made for offering post partum tubal ligation to women who may desire a permanent method of contraception. Postpartum tubal ligation is known to be a safe, cost effective method of contraception [24]. Currently, this is not the policy or practice in the public health institutions in the Gambia.

We demonstrated that $97.1 \%$ of our study participants were aware of the availability of contraception. In fact, $56.6 \%$ of these mothers had been counseled regarding availability, accessibility and various options available for contraception in the hospital before discharge in their previous pregnancy. Majority of them had their last delivery in the hospital (93.4\%) and lived in an urban area (70.6\%). Therefore, inability to use contraception to prevent the occurrence of index pregnancy was not due to lack of contraception or accessibility, rather the beliefs and stories the women heard regarding contraception likely affected willingness to use contraception resulting in the index pregnancy. A study conducted by Adanu et al in the subregion showed that education influences the uptake of modern contraception among women in Sub-Saharan Africa [25]. This is in keeping with our finding as

Table 5 Reasons given for not using contraceptive

\begin{tabular}{llc}
\hline & Frequency & Percentage (\%) \\
\hline Afraid of side effects & 25 & 33.3 \\
Religious beliefs & 12 & 16.0 \\
Did not know about family planning & 4 & 5.4 \\
Did not know where to get & 7 & 9.3 \\
My partner refused & 13 & 17.3 \\
No specific reason & 14 & 18.7 \\
Total & 75 & 100.0 \\
\hline
\end{tabular}


Table 6 Reason for current pregnancy in study participants

\begin{tabular}{llr}
\hline Reasons for index pregnancy & Frequency & Percent \\
\hline Death of another child & 21 & 15.4 \\
Failed Contraception & 11 & 8.1 \\
Gender related & 11 & 8.1 \\
Husband's Wish & 5 & 3.7 \\
Mistake & 25 & 18.4 \\
More Children & 31 & 22.8 \\
No Reason & 17 & 12.5 \\
Others & 3 & 2.2 \\
Remarried & 12 & 8.8 \\
Total & 136 & 100.0 \\
\hline
\end{tabular}

more than $55 \%$ of our study participants did not have any formal education.

While 95 (69.9\%) of the participants were willing to use a contraceptive method at the end of the current pregnancy, $40(29.4 \%)$ were not willing to use any method. This is a known precursor of another pregnancy.

Seventy-five women (55.1\%) reported that their partner would support their decision concerning family planning while $51(37.5 \%)$ felt he would not give support. This is a very important factor as a previous study had shown that strong husband wish is a determinant factor in acceptance and consistent use of contraception [16].

The use of hospital clients as study participants may limit the generalizability of the study. However, it is more likely that those who do not utilize hospital services are more likely to have an unfavourable attitude towards contraception. However, in the Gambian context, more than $90 \%$ of all pregnant women have antenatal care [13]. Therefore, a communitybased study may not differ much.

\section{Conclusion}

In conclusion, grand multiparity is still quite common in The Gambia in spite of the availability of modern contraceptive methods. The most common reason given for the current pregnancy among the grand multiparous was a desire for more children. This is closely followed by those who got pregnant by "mistake". Women need to be informed of the dangers of grand multiparity and advised to practice effective family planning methods to prevent further pregnancy. However, it is imperative to reiterate the importance of quality antenatal care that effectively incorporates the concept of birth preparedness and complication readiness as the effects of these complications can be minimized by good antenatal care. There is however a need to develop family planning messages that specifically target men and religious leaders as they are key opinion leaders and decision makers. Disseminating accurate information on contraceptives to address popular myths on contraception will also be key.. Postpartum contraceptive methods like tubal ligation and the intrauterine contraceptive device should be made readily available and the Gambian reproductive health policy should focus on these methods of contraception in addition to other commonly available contraceptive methods. In the long term, improving access to education for girls will likely reduce the prevalence of grand multiparity.

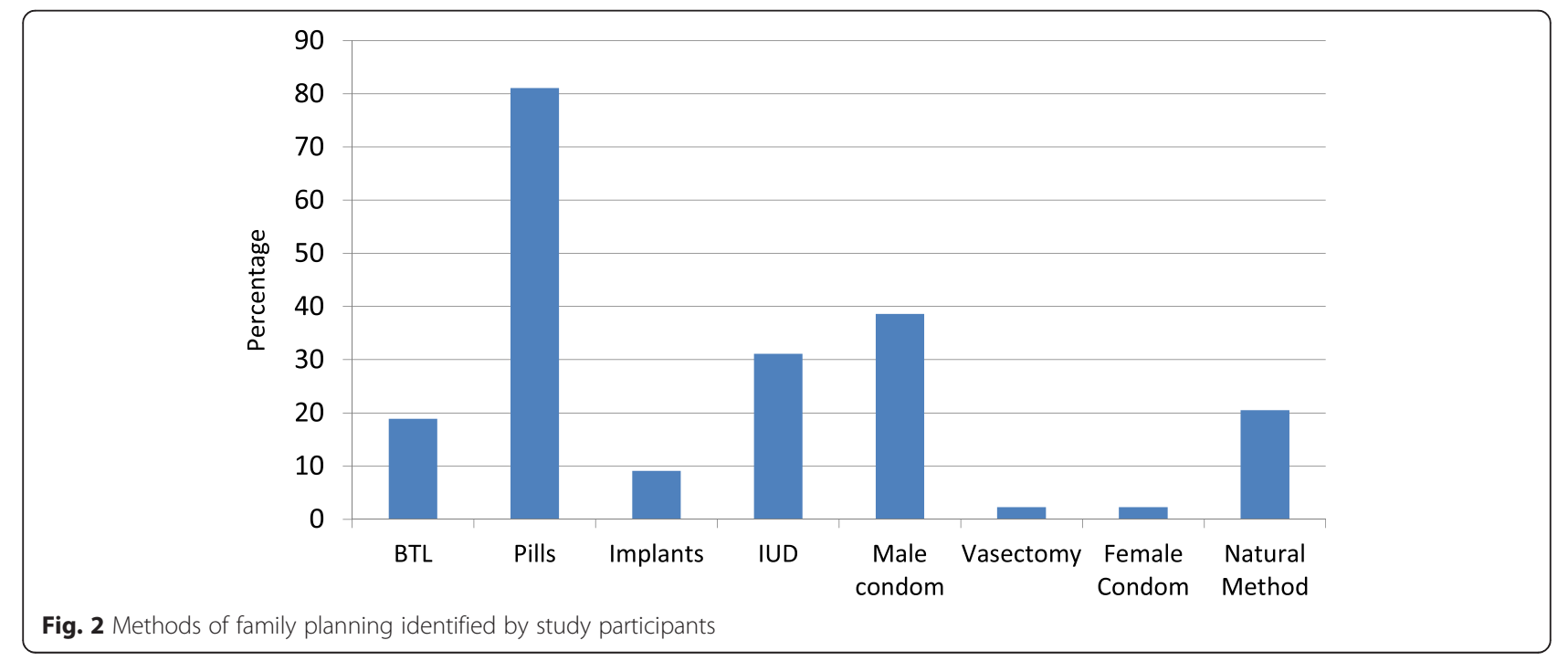




\section{Additional file}

Additional file 1: Questionnaire reasons for current pregnancy amongst grand multiparous Gambian women. (DOC 29 kb)

\section{Abbreviations}

RVTH, Royal Victoria Teaching Hospital

\section{Acknowledgments}

The authors acknowledge the role of Dr Oley Jallow and Ms Assiatou Jallow in translating the questionnaire to the local languages and for help in coordinating the data collection. The authors are grateful to Dr Olubukola T Idoko for reading the manuscripts and offering useful criticisms.

\section{Funding}

The authors did not receive any funding to conduct this study.

\section{Availability of data and materia}

The datasets generated and/or analyzed during this study are available from the corresponding author on reasonable request.

\section{Authors' contribution}

$\mathrm{PI}$ conceived the study and contributed to study design, training of interviewers, data analysis and writing up of the manuscript. GN contributed to the study design, data collection, data entry and writing up of the manuscript. MA contributed to the study design, statistical analysis, and the writing up of the manuscript. All authors read and approved the final manuscript.

\section{Authors' information}

$\mathrm{Pl}$ is an obstetrician/gynaecologist with interest in reproductive health and reducing maternal mortality and morbidity in Africa. GN is a medical doctor who is currently pursuing her interest in public health. MA is an obstetrician/ gynaecologist and a lecturer.

\section{Competing interests}

The authors declare that they have no competing interests.

\section{Consent for publication}

Not applicable.

\section{Ethics approval and consent to participate}

The ethical committee of the Royal Victoria teaching hospital (now Edward Francis Small teaching Hospital) approved the study. Participants were required to sign an informed consent form before participation in the study. Illiterate participants were required to thumbprint the consent forms but needed to have a literate person as witness.

Received: 9 June 2015 Accepted: 2 August 2016

Published online: 11 August 2016

\section{References}

1. Bugg GJ, Atwal GS, Maresh M. Grandmultiparae in a modern setting. BJOG. 2002;109:249-53.

2. Eze JN, Okaro JM, Okafor MH. Outcome of pregnancy in the Grandmultipara in Enugu, Nigeria. Trop J Obstet Gynaecol. 2006;23(1):8-11.

3. Omole-Ohonsi A, Ashimi AO. Grand multiparity: obstetric performance in Aminu Kano Teaching Hospital, Kano, Nigeria. Niger J Clin Pract. 2011;14(1):6-9.

4. Mutihir JT. Obstetric outcome of the Grandmultipara in Jos, Nigeria. J Med Tropics. 2005;7(1):14-20.

5. Ali FA, et al. Caesarean section in Grandmultipara. Mtaer Med Pol. 1996;28(93):87-91.

6. Solomons B. The dangerous multipara. Lancet. 1934;2:8-11.

7. Rayamajhi R, Thapa M, Pande S. The challenge of Grandmultiparity in obstetric practice. Kathmandu Univ Med J. 2006:4(1):70-4

8. Mgaya AH, Massawe SN, Kidanto HL, Mgaya HN. Grand multiparity: is it still a risk in pregnancy? BMC Pregnancy Childbirth. 2013:13:241.

9. Abasiattai AM, Utuk NM, Udoma EJ, Umoh AV. Grandmultiparity: Outcome of delivery in a tertiary hospital in Southern Nigeria. Niger Med. 2011;20(3):345-8.
10. Gharoro EP, Igbafe AA. Grandmultiparity: emerging trend in a tropical community. Trop J Obstet Gynaecol. 2001;18(1):27-30.

11. Yasir R, Perveen FZ, Ali L, Perveen S, Tayyab S. Grand-multiparity still an obstetric risk for developing countries. Med Channel. 2010;16:264-8.

12. Hoque M, Hoque E, Kader SB. Pregnancy complications of Grandmultiparity at a rural setting of South Africa. Iran J Reprod Med. 2008;6(1):25-31.

13. Demographic and Health Survey The Gambia 2013. http://www.gbos.gov. gm/uploads/survey/The\%20Gambia\%20

Demographic\%20and\%20Health\%20Survey\%202013\%20

Preliminary\%20Report.pdf Accessed $25^{\text {th }}$ May 2015

14. World Health Organization. Gambia Health Profile. www.who.int/gho/ countries/gmb.pdf Accessed 27 ${ }^{\text {th }}$ Jan 2015

15. Hoestermann C, Ogbaselassie G, Wacker J, Bastert G. Maternal mortality in the main referral hospital in The Gambia, West Africa. Trop Med Int Health. 1996:1(5):710-7.

16. Anya SE. Seasonal variation in the risk and causes of maternal death in the Gambia: malaria appears to be an important factor. Am J Trop Med Hyg. 2004;70(5):510-3.

17. Kuti O, Dare FO, Ogunniyi SO. Grand multiparity: Mothers' own reasons for the index pregnancy. Trop J Obstet Gynaecol. 2001;18(1):34-7.

18. Obiechina NJA, Ugboaja JO, Ezeama CO. Grand multiparity: reasons for the index pregnancy. Trop J Med Res. 2008;12(2):65-70.

19. Shechter Y, Levy A, Wiznitzer A, Zlotnik A, Sheiner E. Obstetric complications in grand and great grand multiparous women. J Matern Fetal Neonatal Med. 2010;23(10):1211-7.

20. Geidam AD, Audu BM, Oummate Z. Pregnancy outcome among grand multiparous women at the University of Maiduguri Teaching Hospital: a case control study. J Obstet Gynaecol. 2011;31(5):404-8.

21. Al JF. Grandmultiparity: a potential risk factor for adverse pregnancy outcomes. J Reprod Med. 2012:57(1-2):53-7.

22. Maymon E, Ghezzi F, Shoham-Vardi I, Hershkowitz R, Franchi M, Katz M, Mazor M. Peripartum complications in grand multiparous women: para 6-9 versus para > or =10. Eur J Obstet Gynecol Reprod Biol. 1998:81(1):21-5.

23. Nasir SG, Aliyu G, Ya'u I, Gadanya M, Mohammed M, Zubair M, et al. From intense rejection to advocacy: How muslim clerics were engaged in a polio eradication initiative in Northern Nigeria. PLoS Med. 2014;11(8):e1001687.

24. Kennedy KI. Post-partum contraception. Baillieres Clin Obstet Gynaecol. 1996;10(1):25-41.

25. Adanu R, Seffah J, Hill A, Darko R, Anarfi J. Contraceptive use by women in Accra Ghana from the 2003 Accra Women's Health survey. Afr J Reprod Health. 2009;13(1):123-33.

\section{Submit your next manuscript to BioMed Central} and we will help you at every step:

- We accept pre-submission inquiries

- Our selector tool helps you to find the most relevant journal

- We provide round the clock customer support

- Convenient online submission

- Thorough peer review

- Inclusion in PubMed and all major indexing services

- Maximum visibility for your research

Submit your manuscript at www.biomedcentral.com/submit 